\title{
Patient self-management programs in neuromuscular disorders
}

Do they help?

Richard M. Dubinsky, MD, MPH

Neurology ${ }^{\circledR}$ 2019;93:e1745-e1747. doi:10.1212/WNL.0000000000008396

Most patients with nerve and muscle disorders experience chronic fatigue. This can lead to reduced social activity. Other studies have shown that aerobic exercise, cognitive behavior therapy, and conserving energy can help patients who have chronic fatigue from a wide variety of neurologic disorders. The authors wanted to see if these treatments would work for chronic fatigue in patients with nerve and muscle disorders.

\section{How was the study done?}

Veenhuizen and colleagues ${ }^{1}$ reported the results of a scientific study in the Netherlands comparing the use of exercise training to usual treatment in patients with chronic fatigue due to nerve or muscle disorders.

This study was done at 3 locations in the Netherlands. Energetic is a 16-week program that combines aerobic exercise, energy conservation, and relapse prevention. This was compared to the usual treatment for the patients' neuromuscular disorders. The main goal was to look at changes in social activity as measured by the Canadian Occupational Performance Measure (COPM) performance scale. This is a 5-step plan where the patient identifies specific problems and works with a therapist to test if they have improved after an intervention.

The authors also looked at 3 other measures:

1. COPM satisfaction scale

2. Scores on a 6-minute walking test

3. A measure of fatigue

These were measured at the end of the intervention and 3 and 11 months later. Patients did aerobic exercise in three 30-minute sessions a week. This was done both with a physical therapist and at home, over 4 months. The level was aimed at $50 \%-70 \%$ of each patient's maximum heart rate as determined by a cycling test. Patients were to continue these exercises on their own after the 16 weeks of intervention.

There were three 60-minute exercise education sessions on general physical training for people with neuromuscular disorders during the first 3 weeks. There were also eight 90-minute sessions on energy conservation during everyday activities. There were 10 group sessions during the 16 weeks of the study, led by an occupational or physical therapist or a sports trainer, to encourage patients to do these exercises and strategies every day.

\section{What did the researchers find?}

The patients had different neuromuscular disorders. This is good, because the results may apply broadly to many patients with neuromuscular disease. The group participating in Energetic were more satisfied than the usual treatment control group. The COPM score was improved in $21 / 29$ in the Energetic group and in only $6 / 24$ in the control group. Worsening of the COPM

\section{RELATED ARTICLE}

Self-management program improves participation in patients with neuromuscular disease: A randomized controlled trial

Page 784 
was seen only in the control group. The Energetic group also improved on the 6-minute walk test compared to the controls. These good results were also seen at 3 and 11 months after exercise began.

\section{What does this mean for patients with neuromuscular disease?}

Chronic fatigue and weakness from diseases of the nerves, muscles, and their connections are common. The fatigue and weakness can lead to reduced activity, further weakness, and lack of stamina. This can lead to social isolation. Although the patients thought fatigue did not change, differences were seen. Patients receiving the study treatment had more social interaction and improved on the 6-minute walk test. This encouraged patients to take charge of managing the symptoms of a wide variety of diseases of the nerves and muscles. These treatments were done by occupational and physical therapists who required little additional training. Thus this group of treatments can be performed in a variety of settings throughout the world.

\section{Reference}

1. Veenhuizen Y, Cup E, Jonker M, et al. Self-management program improves participation in patients with neuromuscular disease. Neurology 2019;93:e1720-e1731. 


\section{About neuromuscular disorders}

Richard M. Dubinsky, MD, MPH

Neurology ${ }^{\circledR}$ 2019;93:e1745-e1747. doi:10.1212/WNL.0000000000008396

\section{What are neuromuscular disorders?}

Neuromuscular disorders are a group of diseases that involve the nerves, muscles, and their connection, called the neuromuscular junction. Nerves carry information from the world around us to the brain. They send signals from the brain that cause muscles to work. They also control autonomic functions such as breathing, blood pressure, pulse, sweating, and the digestive tract. Muscles move our limbs and bodies. Diseases of the nerve and muscles can result in numbness, abnormal sensations, clumsiness, and reduced strength and stamina.

\section{What causes neuromuscular disorders?}

Nerve and muscle disorders have many different causes. These include diabetes, nutritional problems, immune system attacks against the nerves, muscles, and neuromuscular junction, and toxic effects of medications. Some are due to genetic problems, like the muscular dystrophies. In many of these disorders, the causes are unknown.

\section{Who is likely to have neuromuscular disorders?}

Adults and children across the world have nerve and muscle disorders. Some disorders run in families, such as Charcot-Marie-Tooth disease (a disorder of the nerves) and the muscular dystrophies. Others are caused by diabetes. Some neuropathies are caused by chemotherapy used to treat some forms of cancer. Neuropathies are one of the most common neurologic disorders, affecting people of all backgrounds.

\section{What are the symptoms of a neuromuscular disorder?}

Common symptoms of neuropathy are numbness and tingling in the feet and hands, balance problems, and weakness of the hands and feet. Common symptoms of muscle diseases are weakness with walking, running, going up or down the stairs, muscle cramps, and loss of muscle mass. In neuromuscular junction disorders, common symptoms are double vision, trouble swallowing, weakness with mild exertion, and return of strength after a brief rest.

\section{Can neuromuscular disorders be prevented?}

There are no proven methods to prevent diseases of the nerves and muscles.

\section{How are neuromuscular disorders treated?}

Treatment is usually based on the cause. Nerve, muscle, and neuromuscular junction diseases caused by the body's immune system attacking the nerves or muscles can respond to medications that suppress the immune system. In other disorders, medications are used to treat pain and discomfort. In some, exercises, along with physical and occupational therapy, can decrease the severity of the symptoms and improve quality of life.

\section{Additional resources}

Brain \& Life

brainandlife.org/

Muscular Dystrophy Association

MDA.org

Myasthenia Gravis Foundation of America

myasthenia.org

Foundation for Peripheral Neuropathy

foundationforpn.org 


\section{Neurology}

\section{Patient self-management programs in neuromuscular disorders: Do they help? Richard M. Dubinsky \\ Neurology 2019;93;e1745-e1747 \\ DOI 10.1212/WNL.0000000000008396}

This information is current as of October 28, 2019

Updated Information \& Services

References

Permissions \& Licensing

Reprints including high resolution figures, can be found at: http://n.neurology.org/content/93/18/e1745.full

This article cites 1 articles, 1 of which you can access for free at: http://n.neurology.org/content/93/18/e1745.full\#ref-list-1

Information about reproducing this article in parts (figures,tables) or in its entirety can be found online at:

http://www.neurology.org/about/about_the_journal\#permissions

Information about ordering reprints can be found online:

http://n.neurology.org/subscribers/advertise

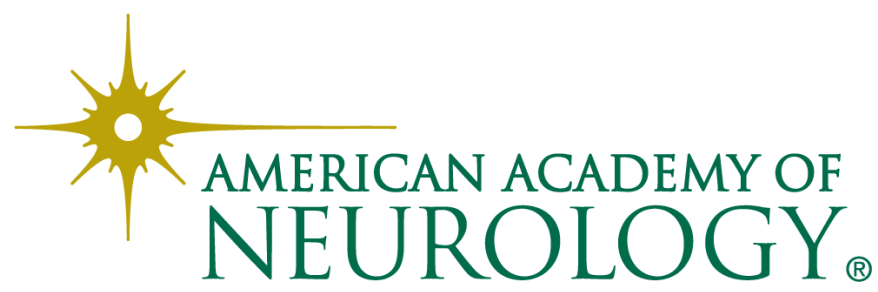

